
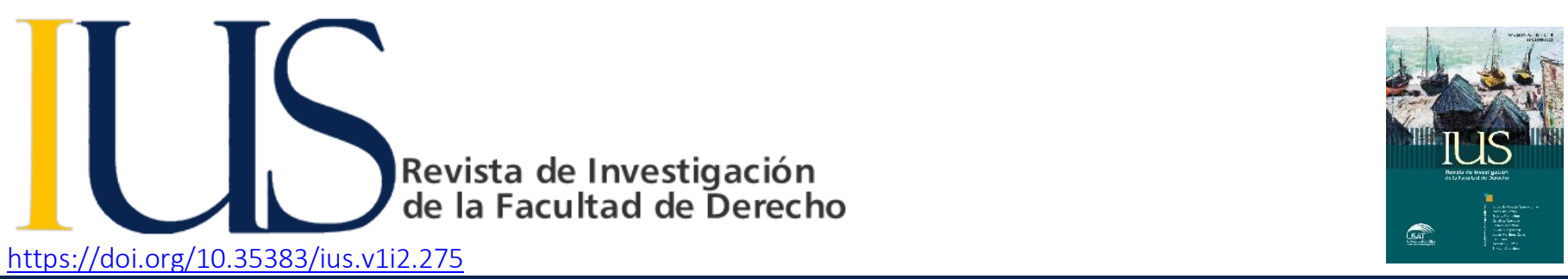

\title{
LA INTERRUPCIÓN DE LA PRESCRIPCIÓN DE LAS ACCIONES LABORALES Y EL PRINCIPIO PROTECTOR
} Javier H. Espinoza Escobar ${ }^{1}$

\begin{tabular}{ll}
\hline INFORMACIÓN DEL ARTÍCULO & RESUMEN \\
\hline Historia del artículo: & A raíz de la Casación Laboral Nº 6763-2017-Moquegua dictada por la Segunda \\
Recibido el 19 de junio de 2019 & Sala de Derecho Constitucional y Social Transitoria de la Corte Suprema de \\
Aceptado el 16 de setiembre de 2019 & Justicia de la República, el autor realiza un análisis de las causales de \\
& interrupción de la prescripción reguladas en el Código Civil y que, dada la \\
\hline Palabras clave: & ausencia de regulación, deben aplicarse supletoriamente al ámbito laboral. El \\
Prescripción laboral & autor manifiesta que esta aplicación supletoria debe efectuarse teniendo en \\
interrupción de la prescripción & cuenta el principio protector propio del ordenamiento laboral para proteger \\
principio protector & los intereses del trabajador
\end{tabular}

The interruption of the prescription of labor actions and the protective principle

\section{ABSTRACT}

\section{Keywords:}

Labor prescription

interruption of the prescription

protector principle

\begin{abstract}
Following the Labor Appeal No. 6763-2017-Moquegua issued by the Second Chamber of Transitional Constitutional and Social Law of the Supreme Court of Justice of the Republic, the author makes an analysis of the causes of interruption of the prescription regulated in the Civil Code that should be used in a supplementary way because of the lack of regulation in the labor law área. The autor states that this supplementary application must be influenced by the protector principle, the most important in the labor área, which guarantees the worker interests
\end{abstract}

\section{Introducción}

En el ordenamiento jurídico peruano, el artículo único de la Ley 27321 (22.07.2000) establece que las acciones por derechos derivados de la relación laboral prescriben a los 4 (cuatro) años, contados desde el día siguiente en que se extingue el vínculo laboral. Como vemos, la citada norma se limita a establecer el plazo para la prescripción de las acciones laborales y el inicio del mismo, sin referirse a otros aspectos y situaciones relacionadas con la prescripción, tales como la suspensión o la interrupción, que sí se encuentran contempladas en el Código Civil peruano.
Por esa razón, tal como se comprueba en la casación objeto de comentario, los jueces recurren al título I del libro VIII sobre Prescripción y Caducidad del Código Civil para resolver, vía aplicación supletoria, una situación de interrupción de la prescripción que, en el caso analizado, implicaba la continuación o la culminación de un proceso judicial sobre pago de beneficios sociales. En efecto, después de que en primera y segunda instancia se declarase fundada la excepción de prescripción formulada por la ex empleadora demandada, la Segunda Sala de Derecho Constitucional y Social Transitoria de la Corte Suprema, mediante la

\footnotetext{
1 Profesor Principal de Derecho del Trabajo en la Facultad de Derecho de la Universidad Católica Santo Toribio de Mogrovejo. Miembro de la Sociedad Peruana de Derecho del Trabajo y de la Seguridad Social. Chiclayo, Perú. Contacto: hespinoza@usat.edu.pe. ORCID: https://orcid.org/0000-0002-9906-0526
} 
Casación Laboral 6763-2017-Moquegua (28.03.2018)², declaró fundado el recurso de casación interpuesto por el trabajador demandante y estableció en su cuarto considerando como criterio jurisprudencial que: "Todo acto por el cual el trabajador dentro del plazo prescriptorio comunique a su empleador la voluntad de reclamar los derechos laborales que considera le son adeudados, constituye una interrupción de la prescripción".

A partir de la citada casación, se realizará un análisis de la interrupción de la prescripción en el ámbito laboral teniendo como idea central que el principio protector propio del ordenamiento laboral debe ser el que informe la aplicación supletoria de las normas sobre interrupción de la prescripción del Código Civil para garantizar que las diversas acciones adoptadas por el trabajador -parte débil de la relación laboral- que evidencien su deseo de hacer efectivo el cobro de las deudas laborales constituyan causa suficiente para interrumpir el plazo prescriptorio.

\section{EL PRINCIPIO PROTECTOR EN EL ÁMBITO LABORAL}

No cabe duda de la especial trascendencia del Derecho del Trabajo en la regulación de la relación jurídica que se origina en el contrato de trabajo.

Esta relación es naturalmente desigual. La prestación personal de servicios realizada por el trabajador a cambio de la remuneración se efectúa bajo el marco de la subordinación al poder de dirección del empleador y la "falta de libertad de quien es contratado -carencia que, a su vez, es consecuencia de su necesidad económica" (Ackerman, 2008, p. 320). De esta forma, queda justificada la necesidad de establecer un ordenamiento jurídico propio y especial para garantizar la dignidad y los derechos fundamentales de la persona que trabaja pues las reglas comunes sobre contratación propias del Derecho Civil se construyen sobre un marco de absoluta libertad e igualdad de las partes que no es propia de la relación laboral.

Este ordenamiento especial es, en esencia, un ordenamiento protector. Dicho de otra forma, un ordenamiento que se funda y construye en base al principio protector entendido como "una directriz política o una preferencia axiológica que reclama que en las relaciones laborales se otorgue una tutela o amparo preferente a las personas que trabajan" (Ackerman, 2008 , p. 319). De allí que el principio protector exigirá del Estado la adopción de las medidas legales necesarias para garantizar y proteger a la persona que trabaja.

Es este el sentido de las disposiciones de la Constitución peruana que, partiendo de reconocer el derecho al

${ }^{2}$ Publicada en la separata de Jurisprudencia del diario Oficial El Peruano del jueves 24 de mayo de 2018. trabajo (artículo 22ㅇ), obligan al Estado a dotarlo de una "atención prioritaria" pues el trabajo constituye base del bienestar social y un medio de realización de la persona. Además, lo obliga a garantizar que ninguna relación laboral limite el ejercicio de los derechos constitucionales, ni desconozca o rebaje la dignidad del trabajador (artículo 23).

Refiriéndose a los artículos $22^{\circ}$ y $23^{\circ}$ de la Constitución, el Tribunal Constitucional ha reconocido el carácter tuitivo del Derecho del Trabajo debido a la falta de equilibrio de las partes de la relación laboral, "Por lo que sus lineamientos constitucionales, que forman parte de la gama de los derechos fundamentales, no pueden ser meramente literales o estáticos, sino efectivos y oportunos ante circunstancias en que se vislumbra con claridad el abuso del derecho en la subordinación funcional y económica" (Sentencia del Expediente № 0628-2001-AA/TC del 2 de julio de 2002, fundamento jurídico 6).

Asimismo, a partir del reconocimiento del trabajador como la parte más débil de la relación laboral, la Corte Suprema de la República afirma que, en virtud del principio protector regulado en el artículo 23ㅇ de la Constitución, "el Derecho del Trabajo apartándose de la igualdad formal existente entre las relaciones de naturaleza civil o mercantil, acude en su ayuda por medio de una disparidad jurídica que permita equiparar la desigualdad existente en la realidad" (Casación Laboral 574-2017-Lima, de 8 de noviembre de 2013).

La disparidad jurídica a la que hace referencia la Corte Suprema se manifiesta en las diversas normas del ordenamiento jurídico y en la interpretación que de ellas se realice buscando que se garantice el acceso al empleo, el desarrollo de la relación laboral y su culminación en un marco de respeto absoluto a la dignidad del trabajador y a sus derechos fundamentales.

De allí que, es absolutamente necesario que el principio protector también irradie las disposiciones que regulan el derecho de acción de los trabajadores para presentar sus reclamaciones por adeudos laborales en el ámbito judicial, sea para facilitar dicha reclamación o sea, para impedir que el trabajador se quede sin la posibilidad de ver satisfechos sus derechos e intereses. Este último aspecto es el que será abordado pues se postula que las disposiciones sobre prescripción de acciones laborales así como las normas supletorias del Código Civil sean interpretadas y aplicadas teniendo en cuenta este principio.

\section{LA PRESCRIPCIÓN EXTINTIVA EN EL ÁMBITO LABORAL}


La prescripción es un instituto jurídico del Derecho que busca afianzar situaciones de hecho, por el transcurso del tiempo, con el objetivo de incorporar en el patrimonio un bien o cosa ajena (prescripción adquisitiva) o extinguir la posibilidad de reclamar un derecho del cual se es titular (prescripción extintiva). A efectos del presente comentario, nos referiremos a la prescripción extintiva de incuestionable aplicación al ámbito laboral y que, de acuerdo con el artículo $139^{\circ}$, numeral 3 de la Constitución peruana produce los efectos de la cosa juzgada.

Según Vidal (2015), la prescripción extintiva "se sustenta en el transcurso del tiempo, y su efecto es el de hacer perder al titular del derecho el ejercicio de la pretensión correspondiente" (p. 898). Nótese que el autor pone énfasis en que es la pretensión la que se extingue con el transcurso del tiempo y no la acción, como erróneamente dispone el artículo 1989 del Código Civil peruano ${ }^{3}$.

Cornejo (2003) afirma que la prescripción "es un mecanismo de extinción de derechos que despliega sus efectos cuando transcurre el tiempo previsto en la ley y cuando el titular del derecho no realiza ninguna actividad para reclamarlo" (p. 288). De esta definición puede deducirse que la prescripción se fundamenta en dos hechos puntuales que deben concurrir para su perfeccionamiento: (i) el transcurso del tiempo, fijado expresamente por la ley; razón por la que el derecho de prescribir es irrenunciable, sancionándose con nulidad todo pacto destinado a impedir sus efectos (artículo 1990o del Código Civil); y. (ii) la inacción del titular del derecho para exigir la satisfacción de su pretensión.

Ariano (2014), considera que el efecto extintivo que produce la prescripción se encuentra bajo la disponibilidad del sujeto pasivo de la relación jurídica pues se requiere, además, la voluntad de quien se puede ver favorecido por la prescripción, esto es, el deudor obligado. Esta afirmación tiene sustento legal en lo establecido en el artículo 1991ㅇ del Código Civil que reconoce la posibilidad de renunciar expresa 0 tácitamente a la prescripción ya ganada; entendiéndose por renuncia tácita cuando el deudor ejecuta actos incompatibles con la voluntad de favorecerse con la prescripción, como por ejemplo, al no hacer valer la prescripción, vía excepción, en el proceso laboral correspondiente.

Situando la figura en el ámbito del Derecho del Trabajo, la prescripción constituye el instrumento a través del cual el trabajador queda imposibilitado de ver satisfecha su pretensión laboral, debido al vencimiento del plazo establecido por la ley 27321 , esto es, cuatro

${ }^{3}$ Código Civil, Artículo 1989: "La prescripción extingue la acción pero no el derecho mismo".
(4) años contados desde el día siguiente de la extinción del vínculo laboral. Como se puede notar, esta regulación difiere de la establecida en el artículo 1993으 del Código Civil según el cual, la prescripción comienza a correr desde el día en que puede ejercitarse la acción. La diferente regulación del inicio del cómputo de la prescripción en la Ley 27321 es consecuencia de la aplicación del principio protector en el ámbito laboral. En efecto, se busca evitar que el trabajador se coloque en una situación incómoda o desventajosa, dada la subordinación a la que se encuentra sometido mientras mantiene el vínculo laboral. En ese sentido, la Sala de Derecho Constitucional y Social Permanente de la Corte Suprema en el considerando sexto de la Casación Laboral № 5490-2012-Tacna (8.04.2013) reconoce que la regulación del inicio del plazo prescriptorio laboral es tal, porque a partir del día siguiente de la extinción del vínculo laboral, el trabajador se encuentra en capacidad real "de reclamar cualquier saldo, reintegro o derecho que el empleador le adeudare y que, por diferentes causas objetivas (desinformación) o subjetivas (temor a fracturar la confianza o buena fe laboral), no pudo reclamar durante la vigencia de la relación laboral".

En la Casación objeto de análisis se ha definido la prescripción laboral desde el punto de vista procesal, como "un medio de defensa (excepción) que el empleador propone contra la demanda de pago de determinados derechos laborales en razón de haber transcurrido el tiempo fijado por ley como prescriptorio de las acciones derivadas de derechos generados a consecuencia de una relación laboral" (Considerando tercero, numeral 1). Es evidente, entonces, que la prescripción la opone el empleador demandado, vía contestación de la demanda como una defensa procesal o de forma.

La Doctrina mayoritaria señala que el fundamento último de la regulación de la prescripción es la seguridad de las relaciones jurídicas y el orden público que constituyen condiciones esenciales para la convivencia social; incluso, se afirma que la prescripción forma parte integrante "de un exclusivo círculo de 'valores de la vida' que son objeto de tutela privilegiada por parte del derecho" (Garmendia, 2002, p.16).

Por ello, Vidal (2015) afirma que "al permitirse la oposición al ejercicio de una pretensión prescrita, se consolidan situaciones que, de otro modo estarían indefinidamente expuestas" (p. 898) más aún si "el ordenamiento jurídico asigna y protege los derechos subjetivos pero no ampara, la desidia, la negligencia ni el abandono" (Monsalvo, 2008, p. 598). 
Ariano (2104), en cambio, manifiesta que los plazos de prescripción no se establecen en aras de una abstracta seguridad jurídica sino a favor del concreto interés del deudor quien no puede estar eternamente bajo la sujeción del acreedor. Por esa razón, la prescripción debe ser alegada por quien se beneficia por ella y el juez tiene impedido fundar sus fallos en la prescripción si esta no ha sido invocada (artículo 1992으 del Código Civil).

Esta cuestión también ha sido reconocida por la Corte Suprema. Así, en el considerando tercero de la Casación Laboral No 5490-2012- Tacna (08.04.2013) se ha establecido que la prescripción protege el valor de la seguridad jurídica en tanto que "despeja toda duda respecto a la exigibilidad de un derecho a lo largo de los años, sancionando al accipiens que dejó (sea por negligencia, descuido o desinformación) transcurrir un determinado plazo sin reclamar el pago de su derecho". En el mismo sentido se ha pronunciado el Tribunal Constitucional. Incidiendo en la seguridad jurídica, el Supremo intérprete considera que la prescripción opera como una sanción frente a la negligencia del acreedor que no puede mantener incierto en el tiempo su derecho a exigir y que permite que "tanto trabajadores como empleadores conozcan los límites temporales de sus obligaciones y derechos" (STC 04272-2006-AA/TC del 12 de noviembre de 2007, fundamento jurídico sexto).

Se podría cuestionar que el instituto de la prescripción afecta el carácter irrenunciable de los derechos laborales reconocidos por la Constitución y la ley dispuesto en el artículo 26으, numeral 2 de la Constitución peruana. No obstante, esta exigencia constitucional no puede mantener latente en el tiempo la posibilidad de reclamar una pretensión de contenido laboral pues "que un derecho laboral sea irrenunciable no implica que sea imprescriptible" (Cornejo, 2003, p. 290), o dicho de otra forma, un derecho laboral será irrenunciable mientras no haya prescrito.

Sobre este asunto, el Supremo intérprete de la Constitución, en el fundamento quinto de la STC $04272-$ 2006-AA/TC (12/11/2007), diferenció entre la irrenunciabilidad de los derechos laborales entendidos como bienes que se encuentran fuera de la disposición incluso de sus propios titulares y la prescripción que es “la 'sanción' legal que se impone al titular de un derecho que, tras su agresión, no ejercita el medio de defensa en un lapso previsto normalmente en la ley". De acuerdo con el Tribunal Constitucional, la prescripción no implica la denegatoria del derecho laboral sino "la restricción del remedio procesal para exigirlo, lo cual no debe olvidarse, constituye también la defensa de otro bien constitucional en la medida que se protege por ésta vía la seguridad jurídica".

En ese mismo sentido se ha pronunciado la Corte Suprema en la Casación Laboral N 5490-2012- Tacna (08.04.2013), al afirmar que aun cuando los derechos laborales están dotados de una protección social reforzada (en virtud del principio protector) "no son inmunes a que el transcurso del tiempo, los torne inexigibles en sede judicial; distinguiéndose así la irrenunciabilidad de la imprescriptibilidad" (Considerando tercero).

\section{INTERRUPCIÓN DE LA PRESCRIPCIÓN}

Como se mencionó anteriormente, el instituto de la prescripción se encuentra regulado de forma más amplia en el Código Civil peruano pues la Ley 27321, aplicable en materia laboral, solo contiene un artículo referido al plazo de la prescripción (4 años) y al inicio del cómputo del plazo prescriptorio (al día siguiente de extinguido el vínculo laboral). No se contempla disposición alguna referida a la interrupción de la prescripción. Por ello, de acuerdo al artículo IX de su Título Preliminar, las disposiciones del Código Civil se aplican supletoriamente a la relación laboral, siempre que no sean incompatibles con su naturaleza.

Esta última afirmación evidencia la necesidad de interpretar las disposiciones del derecho común atendiendo al contenido y finalidad del principio protector característico del ordenamiento laboral. En ese sentido, cabría afirmar que las disposiciones sobre interrupción de la prescripción deben interpretarse y aplicarse buscando posibilitar que el trabajador, parte débil de la relación laboral, pueda accionar en defensa de sus derechos e intereses.

Si la prescripción extintiva se configura por el transcurso del tiempo y por la falta de ejercicio del titular de la pretensión, cualquier acontecimiento que llegue a romper ese silencio justifica que la prescripción ya no se produzca. Esta situación es conocida como interruptio temporis o interrupción de la prescripción y puede ser entendida -de forma general- como cualquier acto de conservación y de defensa del derecho realizado por quien pretende satisfacer judicialmente un derecho o interés. Este acto genera como consecuencia que empiece a correr un nuevo periodo de prescripción y que convierte en ineficaz el tiempo precedente transcurrido (Diez-Picazo, 2007).

Ese efecto de la interrupción lo diferencia de la suspensión de la prescripción que detiene o paraliza el curso de la prescripción "pero con efectos para el futuro, pues se conserva la eficacia del tiempo transcurrido" (Vidal, 2015, p. 901). Superada la causa de suspensión, a diferencia de la interrupción, la 
prescripción continúa su curso tomando en cuenta el plazo previamente transcurrido.

\subsection{Supuestos de interrupción laboral aplicables en materia laboral}

Los supuestos de interrupción de la prescripción son "hechos sobrevinientes al desarrollo del curso prescriptorio" (Vidal, 2015, p. 903). Pueden agruparse en dos tipos: aquellos en los que la causal es reconocitiva, dependiendo de si se originan en la voluntad del prescribiente deudor; o interpelativa, si se originan en la voluntad del titular del derecho que se reclama.

Como se ha afirmado ya, es el artículo $1996^{\circ}$ del Código Civil el que ha establecido las causales de interrupción de la prescripción: 1) Reconocimiento de la obligación; 2. Intimación para constituir en mora al deudor; 3) Citación con la demanda o por otro acto con el que se notifique al deudor, aun cuando se haya acudido a un juez o autoridad incompetente; 4. Oponer judicialmente la compensación.

\subsubsection{Reconocimiento de la Obligación}

Esta causal de interrupción del plazo prescriptorio es resultado de la manifestación de voluntad del deudor de la obligación. Según el artículo $141^{\circ}$ del Código Civil peruano, la manifestación de voluntad puede ser expresa o tácita. Será expresa si se realiza de forma oral, escrita, a través de cualquier medio directo, manual, mecánico, digital, electrónico, mediante lengua de señas o algún medio alternativo de comunicación, incluyendo el uso de ajustes razonables o de los apoyos requeridos por la persona. Es tácita, cuando la voluntad se infiere indubitablemente de una actitud o conductas reiteradas en la historia de vida que revelen su existencia. Estamos, por tanto, frente a una causal de interrupción reconocitiva. Sobre las formas de reconocimiento de una obligación, Morales (2005) agrega:

El reconocimiento de la Obligación puede ser expreso o tácito, debido a la implicancia de la manifestación de la voluntad. La primera forma se materializa cuando se formula oralmente, por escrito o algún otro medio directo, en tanto la manifestación tácita ocurre cuando se infiere indubitablemente de una circunstancia de comportamiento que revela su existencia. (p.355)

Esta causal es plenamente aplicable en el ámbito laboral, sea que el empleador, deudor de una obligación laboral, lo manifieste expresamente, de forma judicial o extrajudicial, en instrumento público o privado; o sea a partir de una conducta o comportamiento indubitable que evidencie tal voluntad. Quizá el problema fundamental que se pueda presentar, cuando la manifestación sea por vía oral es su probanza. En todo caso, tendrá más peso probatorio el reconocimiento que se realice por escrito, en la medida que será de más fácil comprobación.

En ese orden de ideas, importa un reconocimiento expreso de deuda, cualquier pago realizado por el empleador, así se trate de un pago parcial o si está referido solo a los intereses pues "contienen una lógica insoslayable, como es la manifestación del propio deudor en satisfacer la acreencia" (Monsalvo, 2008, p. 636). Mientras que serán ejemplo de reconocimientos tácitos los "comportamientos corroborantes y concluyentes del deudor, de los cuales surja claramente su intención de reconocer el crédito, como por ejemplo, un pedido de espera, promesa de pago, asiento en la documentación comercial o laboral del deudor. (Monsalvo, 2008, p. 637).

\subsubsection{Intimación para constituir en mora al deudor}

Esta causal es calificada por la doctrina como una de interpelación. La intimación en mora está regulada en el artículo $1333^{\circ}$ del Código Civil que, textualmente, establece: "Incurre en mora el obligado desde que el acreedor le exija, judicial o extrajudicialmente, el cumplimiento de su obligación". Aunque la norma menciona que la intimación puede ser judicial o extrajudicial, debido a que el supuesto de reclamación judicial está regulado en el numeral 3) del artículo 1996, entonces lo regulado en el numeral 2) se reduce a los actos de intimación extrajudicial.

De esta disposición se desprende que el deudor incurre en mora en el momento exacto en el que el acreedor, a través de una declaración de voluntad unilateral, requiere al deudor el cumplimiento de la prestación debida. Es necesario, por tanto, que el deudor tome conocimiento de la intimación.

Osterling (2011), refiriéndose a las características de la intimación manifiesta que se trata de una declaración de voluntad unilateral y recepticia, que constituye un derecho potestativo que puede ser formulado por el acreedor, supone una exigencia categórica de cumplimiento y no es formal, en la medida que puede ser realizada por escrito o de forma verbal, correspondiendo al acreedor demostrar fehacientemente su existencia y que el requerimiento llegó a conocimiento del deudor.

En concordancia con lo mencionado por Osterling y teniendo en cuenta que el origen de las deudas requeridas es un contrato de trabajo, debe tenerse en cuenta el artículo $1374^{\circ}$ del Código Civil que precisa que la oferta, su revocación, la aceptación o cualquier otra declaración contractual dirigida a determinada persona se "considera conocida en el momento en que llegan a 
la dirección del destinatario, a no ser que este pruebe que se ha encontrado, sin su culpa, en la imposibilidad de conocerlo". La misma disposición del Código precisa que "Si se realiza a través de medios electrónicos, ópticos u otro análogo, se presumirá la recepción de la declaración contractual, cuando el remitente reciba el acuse de recibo".

En ese sentido, se considera iuris tantum que el deudor ha tomado conocimiento del requerimiento en el momento en que tal requerimiento ha llegado a la dirección del destinatario, "entendiendo esta última como su domicilio" (Osterling, 2011, s/p.). En el caso de la persona natural, el domicilio se constituye por la residencia habitual de la persona en un lugar (artículo $33^{\circ}$ del Código Civil). Si se trata de la persona jurídica, el domicilio será el lugar señalado en su estatuto, donde desarrolla alguna de sus actividades principales o donde instala su administración; no obstante, en caso de discordancia entre el domicilio de la sociedad que aparece en el registro y el que efectivamente ha fijado, se puede considerar cualquiera de ellos (Artículo 20 de la Ley 26887, Ley General de Sociedades).

Un mecanismo muy utilizado para la realización de la intimación en mora es a través de la Carta notarial. De acuerdo con el artículo $100^{\circ}$ del Decreto Legislativo $N^{\circ}$ 1049, Ley del Notariado, “El Notario certificará la entrega de cartas e instrumentos que los interesados le soliciten, a la dirección del destinatario, dentro de los límites de su jurisdicción, dejando constancia de su entrega o de las circunstancias de su diligenciamiento en el duplicado que devolverá a los interesados". Como se puede apreciar, el notario certifica la fecha de emisión y recepción de este documento. De esta manera, se evitan discusiones estériles sobre si la carta llegó o no a tiempo a la dirección del destinatario pues, se dejará constancia de la fecha de recepción de la carta y demás circunstancias relacionadas, entre ellas, las referidas al domicilio donde fue entregada.

No podemos dejar de lado que el propio artículo $1374^{\circ}$ del Código Civil recoge la posibilidad de que cualquier declaración relacionada con el contrato, entre ellas, la relacionada con el requerimiento de pago de derechos y beneficios sociales, propios de una relación de trabajo, pueda efectuarse en el domicilio "virtual" del destinatario. $Y$ es que, como afirma Flores (s/f):

Existen en la actualidad, otros espacios físicos que resultan de un dominio virtual, tal como sucede en el caso de la internet, los correos, casillas y tarjetas electrónicas, inclusive el espacio de memoria que comprenden las aplicaciones de celulares y el mismo celular (p. 13).

En ese sentido, el requerimiento hecho llegar al domicilio virtual del empleador (aquel propio de la persona jurídica, de alguno de sus representantes o de la persona natural empleadora), sea por ejemplo, a través de un correo electrónico, un mensaje de texto dirigido a los teléfonos de los representantes de la empresa, constituirían requerimientos válidos, a efectos de interrumpir el plazo prescriptorio. Una vez más, la principal cuestión se resumirá a la probanza de la realización de la comunicación virtual pues -como establece el artículo $1374^{\circ}$ del Código Civil- se presume la recepción de la declaración contractual cuando el remitente reciba el acuse de recibo. Por esa razón, resulta conveniente que las comunicaciones a través de medios electrónicos se realicen al domicilio virtual "oficial" o de público conocimiento de la empresa, sea que se trate de correos electrónicos, mensajería móvil, cuenta en redes sociales oficial de la empresa, etc. El artículo 1333으 numeral 1) del Código Civil expresa que no es necesaria la intimación para que la mora exista si la ley o el pacto lo declaran expresamente. En relación con esta disposición, parte de la doctrina laboralista ha hecho referencia al artículo $3^{\circ}$ del Decreto Ley 25920 para concluir que en materia laboral no es necesario constituir en mora al deudor. Según el citado artículo, el interés legal sobre los montos adeudados por el empleador se devengan a partir del siguiente de aquél en que se produjo el incumplimiento y hasta el día de su pago efectivo, sin que sea necesario que el trabajador afectado exija, judicial o extrajudicialmente, el cumplimiento de la obligación al empleador o pruebe haber sufrido algún daño.

Comentando esta última cuestión, Dongo (2007) menciona que:

Dicha norma implica la figura de la mora en el ámbito laboral y ésta de por sí, es automática, es decir, a diferencia de una deuda civil, no es necesaria la intimación para que haya exigibilidad, además, en el mismo ámbito laboral trae como consecuencia el pago de los correspondientes intereses. (p.113)

Particularmente, consideramos que del artículo $3^{\circ}$ de la Ley 25920 no se desprende que en el ámbito laboral no sea necesaria la intimación para constituir en mora puesto que esta disposición está referida a la generación automática de intereses legales frente al incumplimiento de pago de montos económicos por 
parte del empleador y no se ha regulado como supuesto de interrupción de la prescripción ${ }^{4}$.

\subsubsection{Citación con la demanda o por otro acto con el que se notifique al deudor, aun cuando se haya acudido a un juez o autoridad incompetente}

Esta causal es de interpelación y expresa el ejercicio del derecho a la tutela jurisdiccional efectiva y el derecho de petición, reconocidos constitucionalmente. Dada la naturaleza de la vía, esta intimación se produce a través de la demanda entendida -de modo genérico- como el documento formal mediante el cual el trabajador o ex trabajador pretende el reconocimiento y protección de un derecho de naturaleza laboral. Se incluyen también las solicitudes de medida cautelar que guarden relación con el reconocimiento anticipado del derecho.

Morales (2016) toma dos posturas con respecto al efecto de la demanda: "i) sirve para intimar en mora judicialmente al deudor - así concuerda con el autor citando anteriormente- $y$ ii) sirve para exigir el respaldo del aparato coercitivo del Estado en el cobro del crédito" (p.100).

De lo establecido en este numeral se desprende que no basta con presentar la demanda para que se configure la interrupción de la prescripción pues, como menciona Cornejo (2003), "Existe la necesidad de la calificación de la demanda por la autoridad jurisdiccional para luego ser notificada a la parte demandada, dicho proceso puede tardar varias semanas, incluso meses" (p.290). Es lo que el Código Procesal Civil denomina el emplazamiento y que, entre otros efectos, interrumpe la prescripción extintiva, tal como lo precisa el artículo 438 o de la citada norma ${ }^{5}$. El emplazamiento o notificación al demandado puede realizarse, a través de cualquiera de las formas reguladas en los artículos 155 y s.s. del Código Procesal Civil, sea mediante cédula, mediante comisión (cuando se notifica a quien domicilia fuera de la competencia territorial del juzgado dentro del país), mediante exhorto (si la parte a notificar se halla fuera del país) o notificación por edicto (si se trata de personas inciertas o cuyo domicilio se ignore).

En la Ley 29497, Nueva Ley Procesal del Trabajo (NLPT), se regulan de forma expresa los diversos momentos en los que se produce el emplazamiento. Así, cuando se trata de un proceso ordinario laboral, el artículo $42^{\circ}$ de la citada norma establece que, verificados los requisitos de la demanda, el juez emite resolución disponiendo: “(..) el emplazamiento al demandado para que concurra a la audiencia de conciliación con el escrito de contestación y sus anexos. De la misma forma, el

\footnotetext{
${ }^{4}$ En el mismo sentido, Del Águila, R (2003). La prescripción extintiva y su aplicación en el ámbito laboral. Actualidad Jurídica, 111, pp. 34-35.
}

artículo 48을 establece que, cuando se trata de un proceso abreviado laboral, previa verificación de los requisitos de la demanda, el juez emite resolución disponiendo: “(...) b) el emplazamiento al demandado para que conteste la demanda en el plazo de diez (10) días hábiles. Cuando se trata de demandas planteadas ante la Sala Laboral, el artículo 51 을 establece que, verificados los requisitos de la demanda, la Sala Laboral emite resolución disponiendo: “(...) b) el emplazamiento al demandado para que conteste la demanda en el plazo de diez (10) días hábiles".

Teniendo en cuenta que la regulación de las causas de interrupción de la prescripción se encuentra en una norma del Derecho Civil conviene recordar que el Derecho del Trabajo tiene una clara vocación tuitiva a favor del trabajador; razón por la que debe ser este principio el que informe las normas civiles aplicables supletoriamente en el ámbito laboral, como son las normas sobre interrupción de la prescripción.

Desde esta visión protectora consideramos que si la interrupción de la prescripción se genera cuando el titular de una pretensión, "rompe su silencio" realizando cualquier acto que evidencia la conservación y defensa de su derecho; entonces, el solo acto de la presentación de la demanda (entendida del modo más amplio, para incluir por ejemplo, las solicitudes cautelares) debe generar la interrupción de la prescripción laboral, sea que la demanda se declare inadmisible por defectos formales, sea que se presente ante juez incompetente -como se establece en el numeral bajo comentario-. Cobra especial protagonismo el artículo III del Título Preliminar de la NLPT referido a que el juez debe realizar una labor interpretativa que favorezca la continuidad del proceso. La cuestión central en la interrupción de la prescripción es que se evidencie el interés del acreedor - trabajador por hacer efectivo el cobro de las obligaciones laborales adeudadas a través del escrito de demanda que contiene la pretensión o pretensiones exigidas. Siendo la presentación de la demanda un acto de parte, es lógico y de justicia que sea aquella y no el emplazamiento al demandado el que genere la interrupción de la prescripción pues este último es un acto procesal que depende del órgano jurisdiccional y puede sufrir una serie de retrasos y demoras no imputables al demandante.

Que la interrupción de la prescripción se produzca con la presentación de la demanda y no con su notificación fue objeto de pronunciamiento en el Pleno Jurisdiccional Nacional Laboral de 1999 realizado en la

${ }^{5}$ Código Procesal Civil, artículo 438: El emplazamiento válido con la demanda produce los siguientes efectos (...) 4 . Interrumpe la prescripción extintiva". 
ciudad de Trujillo en el que se decidió -por mayoría absoluta- que el plazo de prescripción de las acciones por derechos derivados de la relación laboral se interrumpe con la presentación de la demanda ante el órgano jurisdiccional ${ }^{6}$.

Sobre el particular, Morales (1999) sustenta:

Si la prescripción se produce por la inacción del acreedor dejando vencer el plazo establecido por la ley, no puede castigársele con la pérdida del derecho a recibir tutela por el Estado si presentada la demanda dentro de dicho período, el tiempo que transcurre posteriormente corresponde a la actividad que debe cumplir el Juez, calificar la demanda, admitirla y disponer se notifique al emplazado. Contra esta actividad propia del servicio de la administración de justicia no está prevista la prescripción a que se refiere la norma laboral. (pp. 15-16)

Junto con la citación con la demanda, el numeral 3) del artículo 1996 considera causal de interrupción a cualquier "acto con el que se notifique al deudor, aun cuando se haya acudido a un juez o autoridad incompetente". Queda la duda si el citado numeral está referido a cualquier otro acto de notificación dentro de un proceso judicial; cuestión a la que ya nos hemos referido previamente y que queda sin sustento por el hecho de que no importa la notificación al demandado sino la sola presentación de la demanda.

La expresión "autoridad incompetente" parece sacarnos del ámbito judicial y reconducirnos a otros mecanismos de solución de conflictos laborales, tal como ocurre con la conciliación extrajudicial y el arbitraje.

En ese sentido, al igual que ocurre con la presentación de la demanda ante el Poder Judicial, la presentación de una solicitud de conciliación ante los Centros de Conciliación gratuitos del Ministerio de Justicia, los

\footnotetext{
${ }^{6}$ En el ámbito de la jurisdicción Civil, el Pleno Jurisdiccional Nacional Civil y Procesal Civil del año 2016 concluyó que: "En el caso de interposición de la demanda dentro del plazo prescriptorio que establece la ley, pero notificada después de transcurrido el mismo, no se produce la prescripción de la acción". Similar criterio se ha recogido en la Casación $\mathrm{N}^{\circ}$ 12736-2016- Lima Este (28.09.2017) publicada el 31 de agosto de 2018 en el diario Oficial El Peruano. A partir de la valoración de principios y derechos constitucionales como el de tutela jurisdiccional efectiva se ha establecido que "la sola interposición de la demanda interrumpe el término prescriptorio" (Considerando 5.9) porque asumir lo contrario obligaría al demandante "a soportar las consecuencias de la demora judicial en la calificación de la demanda, admisión y su posterior notificación, que constituyen externalidades que no están al alcance de los justiciables el poder controlarlos, lo cual evidentemente vulnera el derecho a la tutela jurisdiccional efectiva, que constituye un derecho fundamental" (considerando 5.8.).
}

centros de conciliación administrativa del Ministerio de Trabajo o centros de conciliación privados; así como la presentación de una demanda ante la autoridad arbitral deben recibir el mismo tratamiento que otorga la norma a las demandas presentadas ante el Poder Judicial; esto es, deben producir la interrupción de la prescripción ${ }^{7}$ pues evidencian el interés del acreedor de exigir su derecho.

Otra cuestión adicional que debe tenerse en cuenta está referida a si la presentación de una denuncia o queja en el ámbito administrativo laboral por parte del acreedor de un derecho con contenido laboral puede considerarse como un acto que interrumpe la prescripción.

Sobre el particular, mediante Ley 29981 (15.01.2013) se creó la Superintendencia Nacional de Fiscalización Laboral - SUNAFIL, como organismo técnico especializado, adscrito al Ministerio de Trabajo y Promoción del Empleo, responsable de promover, supervisar y fiscalizar el cumplimiento del ordenamiento jurídico socio laboral y el de seguridad y salud en el trabajo; así como brindar asesoría técnica, realizar investigaciones y proponer la emisión de normas sobre dichas materias.

En cumplimiento de esas funciones, la SUNAFIL recibe las denuncias por presunta vulneración de las normas en materia socio-laboral, seguridad y salud en el trabajo, derechos fundamentales y seguridad social y realiza el procedimiento de inspección laboral regulado por la Ley № 28806, Ley General de Inspección del Trabajo, y su reglamento, aprobado por Decreto Supremo № 019-2006-TR-Reglamento de la Ley General de Inspección del Trabajo y demás normas modificatorias y complementarias; entre ellas, la Resolución de Superintendencia Na 190-2017-SUNAFIL del 15 de setiembre de 2017 que aprueba la Directiva

${ }^{7}$ Cabe precisar que, contrariamente a la regulación del Código Civil, en el artículo $19^{\circ}$ de la Ley 26872, Ley de Conciliación, se ha regulado que la presentación de la solicitud de conciliación constituye una causal de suspensión de la prescripción y no de interrupción. Así se ha establecido: "los plazos de prescripción establecidos en la normatividad vigente se suspenden a partir de la fecha de presentación de la solicitud de Conciliación Extrajudicial hasta la conclusión del proceso conciliatorio conforme al artículo 15". El Decreto Legislativo 910, Ley General de Inspección del Trabajo y Defensa del Trabajador, en su artículo 28, se refiere erróneamente- a los plazos de caducidad más no a los de prescripción: "El plazo de caducidad en materia laboral, se suspende a partir de la fecha en que cualquiera de las partes precisadas en el artículo anterior presenta la solicitud de Audiencia de Conciliación y hasta la fecha en que concluya el procedimiento". 
Na 002-2017-SUNAFIL/INII - "Servicio de atención de denuncias laborales".

En el numeral 4.1. de la mencionada Resolución de Superintendencia se regula la denuncia laboral como una de las formas de ejercicio del derecho de petición del ciudadano, mediante el que se comunica a la Autoridad Inspectiva del trabajo determinadas conductas que, por acción u omisión, calificarían como una posible infracción. La denuncia puede presentarse de forma verbal o escrita; en este último caso, por mesa de partes de cualquiera de las oficinas de la Intendencia Regional o a través de la página web de la Autoridad Inspectiva del Trabajo.

Cabe precisar que de acuerdo con la citada directiva (Numeral 7.1.1.), la denuncia puede ser presentada por cualquier persona natural (trabajador, extrabajador, o cualquier persona) o jurídica (organización sindical, cualquier entidad pública), sin necesidad de que sea el trabajador que la formule.

Está claro que estas denuncias pueden contener incumplimientos de pago de obligaciones de carácter laboral, por lo cual cabría preguntarse si presentada la denuncia se interrumpe el plazo de prescripción laboral. Sobre esta cuestión, Puntriano (2018) considera que la queja administrativa no debería interrumpir el plazo prescriptorio, pues solo se estableció como criterio vinculante lo expresado en el considerando cuarto en el que no se hace referencia a la queja administrativa; además, afirma que la presentación de la queja no requeriría que el empleador sea notificado lo cual generaría inseguridad jurídica. Sin embargo, consideramos que, al igual que ocurre con la presentación de la demanda en el ámbito judicial o arbitral o con la solicitud de conciliación administrativa ante la autoridad de trabajo o en centro privado, la presentación de una denuncia relacionada con el incumplimiento de las obligaciones laborales constituye una clara manifestación del interés del trabajador denunciante por hacer efectivo el cumplimiento de la obligación por parte del empleador. Por esa razón, y teniendo en cuenta el principio protector, el plazo prescriptorio debe interrumpirse, siempre y cuando, la denuncia sea presentada por el propio trabajador acreedor de la prestación laboral pendiente de pago o por quien este haya designado, vía mecanismo de representación. Téngase presente, que la denuncia generará una orden de inspección que activará todo el procedimiento de inspección laboral regulado en las normas correspondientes y que el inspector, después de constatar el incumplimiento de una norma socio laboral, puede imponer una medida inspectiva de requerimiento, exigiendo al empleador el cumplimiento de la obligación socio laboral incumplida dentro de un plazo determinado.

\subsubsection{Oponer judicialmente la compensación}

De acuerdo con el artículo $1288^{\circ}$ del Código Civil, la compensación constituye una forma de extinción de obligaciones recíprocas, líquidas, exigibles y de prestaciones fungibles y homogéneas, hasta donde respectivamente alcancen.

Exige que dos personas sean respectivamente acreedora y deudora una de la otra. Como es evidente, esta causa de interrupción exige que el trabajador mantenga frente al empleador una obligación líquida, exigible y de prestación fungible y homogénea deudas que pueda ser compensada pero que, además, sea opuesta en vía judicial. Estamos también frente a una causal interpelativa.

Sobre la compensación, Del Águila (2003) sostiene que es poco frecuente que el trabajador tenga obligaciones económicas frente a su empleador; pero además debido a que "los beneficios laborales son intangibles y no pueden ser renunciados, parecería en principio que esta causal sería de escasa aplicación en materia laboral" (p. 36). No obstante -tal como regula el TUO de la Ley de Compensación por Tiempo de Servicio en el artículo $47^{\circ}$, es posible compensar con la CTS las sumas adeudadas por los trabajadores a sus empleadores al cese por concepto de préstamos, adelantos de remuneración, venta o suministro de mercadería producida por su empleador, siempre que no exceda en conjunto del $50 \%$ del beneficio.

Esta causal exige que, frente a una demanda planteada por el empleador contra su trabajador por una obligación existente, válidamente originada y exigible, este oponga la compensación correspondiente con las obligaciones que aquel mantenga pendientes de pago. Es evidente que el Juez debe garantizar que las obligaciones recíprocas sean líquidas y exigibles para evitar la afectación de los derechos del trabajador.

Finalmente, como afirma Morales (2016):

Este tipo de compensación - interruptor del decurso prescriptorio- se da durante la vigencia del derecho a accionar por parte del trabajador, pues una vez que la acción se ha extinguido la compensación no podrá interrumpir plazo alguno aunque sí será amparada por sustentarse en un derecho subsistente (p.102).

\section{Apuntes finales}

Como se manifestó al inicio del presente artículo, en el Considerando sétimo de la Casación Laboral N 6763 2017-Moquegua se ha precisado que el criterio establecido en el Considerando Cuarto, esto es, que "Todo acto por el cual el trabajador dentro del plazo 
prescriptorio comunique a su empleador la voluntad de reclamar los derechos laborales que considera le son adeudados, constituye una interrupción de la prescripción", constituye doctrina jurisprudencial y, por tanto, un precedente de obligatorio cumplimiento por las instancias inferiores, por mandato del artículo 22 de la Ley Orgánica del Poder Judicial.

Consideramos adecuada la doctrina jurisprudencial vinculante de la Corte Suprema, por cuanto -al margen del reconocimiento de las obligaciones por parte del empleador que también constituye una causal de interrupción-, toda actuación del trabajador que evidencie su voluntad e interés por reclamar sus derechos laborales debe ser causa suficiente para interrumpir el plazo prescriptorio.

No obstante, se debe efectuar una precisión sobre lo manifestado por la Corte Suprema, pues pareciera que se hace imprescindible la notificación al empleador para que se produzca la interrupción de la prescripción. Salvo el supuesto referido a la intimación extrajudicial para constituir en mora en el que, de conformidad con el artículo $1374^{\circ}$ del Código Civil, es necesario que el deudor empleador tome conocimiento de la intimación, tanto si se trata de notificación al domicilio real como al domicilio virtual; en el supuesto contemplado en el numeral 3) del artículo $1996^{\circ}$ del Código Civil, esto es la "citación con la demanda o por otro acto con el que se notifique al deudor, aun cuando se haya acudido a un juez o autoridad incompetente", bastará con la sola presentación de la demanda o solicitud cautelar ante el Poder Judicial o Tribunal arbitral o con la sola presentación de la solicitud de conciliación ante un ente administrativo o privado para que se produzca la interrupción del plazo prescriptorio, siempre que se realice dentro del lapso establecido en el artículo único de la ley 27321, esto es, dentro de los 4 años contados desde el día siguiente en que se extingue el vínculo laboral, aun cuando la notificación o comunicación al empleador se realice con posterioridad al vencimiento de dicho plazo.

De la misma forma, la expresión "todo acto" es lo suficientemente amplia para que los mismos efectos descritos para el caso de la presentación de la demanda se apliquen a las quejas o denuncias administrativas presentadas por el trabajador (o quien lo represente) ante la SUNAFIL.

Esto es fundamental por cuanto el principio protector exige que lo que se tome en cuenta para interrumpir el plazo prescriptorio sea la acción del trabajador que evidencie su interés por requerir el pago de lo adeudado. Lo contrario, implicaría someter la acción del trabajador a la oportuna y diligente notificación o comunicación del requerimiento al empleador realizada por el Poder Judicial, el Tribunal Arbitral, el centro de conciliación o la SUNAFIL, esto es, someter la voluntad del trabajador a cuestiones externas no imputables que, de realizarse fuera del plazo prescriptorio, perjudicarían sus derechos e intereses.

\section{Bibliografía}

Ackerman, M. (2008). Los principios en el Derecho del Trabajo. En M. Ackerman (Dir.). Tratado de Derecho del Trabajo. Tomo I. Teoría General del Derecho del Trabajo La relación individual de trabajo - III. (pp. 307-324). Santa Fe: Rubinzal Culzoni.

Ariano Deho, E. (2014). Reflexiones sobre la prescripción y la caducidad a los treinta años de vigencia del Código Civil. Themis, 66, 329-336.

Cornejo Vargas, C. (2003). Algunos apuntes sobre la prescripción laboral en la experiencia legislativa y jurisdiccional peruana. Themis, 46, 287-297.

Del Águila Vela, R. (2003), La Prescripción extintiva y su aplicación en el ámbito laboral. Actualidad Jurídica. 111, 19-45.

Diez Picazo, L. (2007). La prescripción extintiva. En el Código Civil y en la jurisprudencia del Tribunal Supremo. Navarra: Thomson Civitas.

Dongo Ortega, D. (2007). La prescripción Extintiva en los Derechos Laborales. Editorial ADRUS S.R.L. Arequipa.

Flores Flores P. (2015). El perfeccionamiento de contrato entre ausentes. Un análisis al artículo 1374 del Código Civil (Artículo Preliminar). Lima: USMP, Facultad de Derecho, Instituto de Investigación Jurídica. Descargado de http://www.derecho.usmp.edu.pe/sapere/edici ones/edicion 10/articulos investigadores/LA P ERFECCION CONTRATO TERMINADO ALUMNO PAVEL.pdf.

Garmendia M. (2002) Cinco temas sobre prescripción de los créditos laborales. Montevideo: Fundación de Cultura Universitaria.

Monsalvo M. (2008). Extinción de los créditos laborales. En M. Ackerman (Dir.). Tratado de Derecho del Trabajo. Tomo IV. La relación individual de trabajo - III. (pp. 595-654). Santa Fe: Rubinzal Culzoni.

Morales Corrales, P. (2005). Prescripción y caducidad en las acciones laborales. En Sociedad Peruana del Derecho del Trabajo y Seguridad Social. Aportes para la reforma del proceso laboral peruano. (pp. 329-364). Lima: SPDTSS.

Morales Gonzales, N. (1999). Interrupción de la prescripción laboral (Pleno Jurisdiccional Laboral. 
Trujillo - Agosto 1999. Asesoría Laboral, 107, 1516.

Morales Rojas, F. (2016) La prescripción de la acción laboral y la revalidación de la pretensión en el derecho procesal civil. Tesis para optar en el grado de Maestro en Derecho. Universidad Nacional de Trujillo. Trujillo.

Osterling Parodi, F. (2011). Comentarios a los artículos 1333, 1335, 1336 y 1337 del Código Civil peruano. Descargado de http://www.osterlingfirm.com/Documentos/arti culos/ART\%20\%201333\%201335\%201336\%201 337.pdf

Pacheco Zerga. L. (2009) La Prescripción de los Derechos Laborales. Un análisis desde la jurisprudencia. Diálogo con la Jurisprudencia. N¹25, p.p. 245-252.

Puntriano Rosas C. (2018). El castigo a la inacción o prescripción de deudas laborales. Descargado de http://www.infocapitalhumano.pe/columnistas/l a-palabra-del-laboralista/el-castigo-a-lainaccion-o-prescripcion-de-deudas-laborales/

Toledo Filho M. (2013) Prescripción de acciones laborales: cuestiones de fondo y de forma. Derecho PUCP (70), p.p. 371-377.

Vidal Ramírez, F. (2015). Prescripción y Caducidad. En D. Revoredo (comp.), Código Civil: Exposición de Motivos y Comentarios. Tomo VI. (pp. 898-908). Lima: ECB Ediciones S.A.C. 